\title{
The Teaching of Moral Education through Media Education
}

\author{
C. K. Cheung \\ The University of Hong Kong, Hong Kong
}

\begin{abstract}
During the past few decades, the mass media in Hong Kong have moulded the environment in which its citizens now live. The impact of media has particularly affected our pupils. The strong influence of the mass media is, of course, not unique to Hong Kong, but is a worldwide phenomenon. What can we do when the mass media exert such a great influence on pupils? One proposal has been for the introduction of a new school subject: media education. This paper attempts to argue for the teaching of moral education through media education. It first describes the development of moral education in Hong Kong, then looks at the aims of media education, and teaching content and pedagogy, as important reasons of practicing moral education through media education. It uses a study of a secondary school and a primary school to illustrate its arguments.
\end{abstract}

To educate a person in mind and not in morals is to educate a menace to society.

(Theodore Roosevelt)

Philosophers, educators, and parents have defined the aims of education for every generation. Although definitions have varied over time, and Plato's definition in the 4th century BC is not the same as Dewey's more recent formulation, the basic aims are more or less the same: to equip pupils with the knowledge and skills to find a job in the future; to help them better adjust to society both as pupils and as future producers, consumers, and citizens; to teach them virtues so they could be responsible and moral citizens; and to equip them to better society (Whitehead, 1967; Marples, 1999). It is not easy to prioritise these different aims, or to measure whether schools have achieved them. Nevertheless, principals or parents will say, if asked, that it is important that pupils be taught to display acceptable moral behaviour; and every school will find ways to make sure moral education is implemented.

In Hong Kong, the overall aims of education were set out in School Education in Hong Kong: A Statement of Aims (EMB, 1993) as:

To enable everyone to develop his/her potential to the full according to his/her characteristics in the moral, intellectual, physical, social and aesthetic domains so that each individual is ready for continuous self-learning, thinking, exploring, innovating and adapting to changes throughout his/her life; filled with self-confidence and team spirit; and is willing to strive incessantly for the prosperity, progress, freedom, democracy and the rule of law of the 
society, and to contribute to the future well-being of the nation and the world at large.

Nearly every school in Hong Kong claims to provide moral education as part of their curriculum, but a closer examination of the school's timetable reveals that the time given to the teaching of moral education is very limited, and often gives way to the study of academic subjects. What is more, even if moral education is taught, teachers find it difficult to teach values and attitudes while pupils find moral lessons boring. It is particularly the case in this age when pupils, the MTV generation, are exposed to the ever-present bombardment of the mass media. Compared with the flashy shots and juicy contents of mass media programmes, normal lessons seem boring. Exposed to media messages, pupils may be imperceptibly but strongly influenced by the values behind such media messages. Since this is the case, what can be done? The idea of media education is suggested (Cheung, 2006).

\section{Aims of Moral Education in Hong Kong: From the Past to the Present}

Morality and moral virtues are central to Chinese culture. Moral education from ancient times has been a central concern in Chinese education. Historically, the Chinese have believed that the ultimate goal of education is to produce a sound moral character (Cheng, 1951, p.257), and that schools are an important agent of moral education.

Although moral education is supposed to be of great importance to schools in Hong Kong, in reality it seems to be of less importance compared to the pursuit of academic knowledge. In 1981 the General Guidelines on Moral Education in Schools were introduced to devise a new program of moral education in schools. However, the Guidelines did not establish a formal curriculum on moral education for schools, but required them to promote moral education through and across the entire school syllabus.
Though these were the only guidelines on moral education for over 20 years, the Education Department regularly offers advisory services, workshops, and seminars on moral education for teachers. Furthermore, more comprehensive references on moral education were published within this period. Moral education is of prime concern to both the government and educators, and the sentiment is be reflected in various Education Commission Reports. For example, The Education Commission Report 7 (1996) stated that the aim of education is to promote 'a wholeperson education' and 'well-balanced education', which is to enrich every child in moral, intellectual, physical, social and aesthetic knowledge (9); and in Learning to Learn: Report on the Direction of the Curriculum Development (CDC, 2001a), long-life learning and whole-person development are set to be the main directions of the curriculum development in schools for the coming years. The emphasis on moral and civic education is obvious. Chapter 3 of the Report talks about 'Five essential learning experiences' to achieve whole person development, including moral and civic education (p.18). The other four learning experiences are intellectual development, community service, physical and aesthetic development, and careerrelated experience.

Although the government and educators are concerned about moral education, and every school in Hong Kong claims to provide moral education in one way or another, the reality is that moral education takes second place to other subjects due to heavy academic demands on pupils to pass examinations. Except for some schools, which offer Moral Education as an independent subject, most schools claim to have adopted a permeation approach to the teaching of moral education. Some could claim that moral education is inculcated through the teaching of almost any subject in schools, though some subjects lend themselves more readily to this kind of teaching than others. Others claim to have practiced moral education through talks in school assemblies, activities in class periods, and extra-curricular activities. 


\section{Practicing Moral Education through Media Education}

The HKSAR Government's Director of Education said the following at the Seminar on Moral Education for Youth in the New Century (2001):

In setting the direction for moral education for the 21 st century, due regard has been given to the local context and the role of Hong Kong in the world. As pupils' values formation is the result of the interplay between their personal experiences and the societal environment at large, our moral education curriculum is designed with the vision for pupils to perceive themselves not only as individuals but also as members of the society, the nation, and as global citizens.

These words echoed what Niblett (1963) had said four decades ago 'Moral education is rarely more needed than during a period of rapid social change' (p.16). We have entered a new millennium characterized by rapid advances in science and information technology. We are faced with new challenges springing from the impact of increasing globalization and the advent of a knowledge-based economy, which has brought a new dimension to literacy as the ability to construct meaning from text. As knowledge becomes abundant, it is imperative for us to learn the right things.

Social change has brought with it complex problems and controversial moral issues, posing a challenge to our pupils every day. Furthermore, the unbridled influence of the media has a demoralizing effect on our young people as a result of their undue exposure to the sensationalism, violence, bloodshed, and pornography through their day-to-day encounters. All these pose an array of moral challenges to our youngsters who may feel lost, confounded and bewildered, given the many conflicting values.

The strong influence of the mass media on pupils, poses a challenge to educators in moral education.
Instead of preventing pupils from being exposed to the media, can we make use of media education to teach moral education? It is noted that many writers stress the importance of media education in the learning and teaching of moral education (Browning, Miller-McLemore, Couture, Brynoff \& Franklin, 1997; Stout 2001). According to a survey by Cheung (2004), quite a number of teachers from both primary and secondary schools noted that media education could be introduced during moral lessons.

\section{Their Similar Aims}

The United Nations Educational, Scientific and Cultural Organization (UNESCO) first defined media education as:

...the study, learning and teaching of, and about, the modern media of communication and expression as a specific and autonomous area of knowledge within educational theory and practice, distinct from their use as aids for the teaching and learning of other areas of knowledge, such as mathematics, science and geography (IFTC, 1977, p. 3)

According to Minkkinen and Liorca (1978, p.17), the main and general objective of media education is to act 'as a means of helping children and adolescents to receive and understand television programs, films and other products of the media as a whole.' In Britain, Masterman (1992, p.102) states that the most crucial aim of media education is 'to develop in pupils enough self-confidence and critical maturity to be able to apply critical judgments to media texts which they will encounter in the future.'

The aims of media education, as discussed above, can align closely with the aims of moral education, as both are concerned with values and the development of pupils' powers of discernment and judgment. In Hong Kong, under the recent curriculum reform, Ethics and Religious Studies is taught under Personal, Social, and Humanities Education, and the following description is 
noted: 'A holistic perception of moral and civic education covering various issues related to value development such as sex education, environmental protection, media education, religious education, ethics and healthy living is proposed for promotion in schools' (CDC, 2001b, p.84).

\section{Teaching Content and Pedagogy}

Another reason why the teaching of moral education could be taught through media education is related to the teaching content and pedagogy. In fifth century AD, Pope Gregory the Great gave the following advice to missionaries preparing to preach to the barbarians:

If you allow them to give outward expression to their joy in the same way, you will more easily lead them to know inner joy, for be assured that it is impossible to rid such deluded souls of all their misconceptions at once (Crawford \& Rossiter 1988, p.1).

Nowadays, in the teaching of moral education, teachers should know about teenage culture. They should realize that they are dealing with pupils of a culture, which is very different from theirs. They should build links between the cultures of teenagers, a culture of which they may be largely unaware or to which they may have little access and the contents of moral education.

It is noted that moral education involves more than knowledge. Lessons in moral education should be personal and not academic. Teachers should not only concern themselves with what they teach but also with how they teach and interact with pupils, taking care they do this in a way that is meaningful and relevant to pupils. The teaching pedagogy is of prime importance.

For moral education, which is perceived by pupils as boring and indoctrinating, efforts should be made to ensure the relevance and interest of the teaching materials chosen. Teachers are advised to select suitable topics from newspapers, TV programs, movies, and advertisements, forming the basis for useful discussion. The teaching of values cannot be done simply by precept. It must enlist the pupils' own participation, so they can learn in a meaningful, rather than in a rote manner. Whether moral lessons are effective or not may depend on the amount of participation on the part of pupils. Pupils are more likely to take part in topics that they find relevant and interesting. If teachers want their pupils to take seriously value-related aspects of the subject, they have to find ways into pupils' experiences, which may be surprisingly different from their own (Bassett, 2000). Cheung's research (2003) concludes that teachers and pupils enjoy the use of popular culture in the teaching and learning of moral education. A similar approach is suggested by the Hong Kong Education Department. Under the section of general approach to teaching of moral education in schools, it is proposed that teachers need to be in tune with the social as well as intellectual needs of their pupils and should be aware of the many and varied avenues open to them for providing guidance at different stages in a pupil's school life. It is also recommended by the Curriculum Development Council that teachers should 'adopt appropriate teaching strategies in line with the interest and abilities of pupils as well as the teaching environment' (CDC 1999, p.57).

This is exactly what media education will do. Media education focuses much on the learning experiences and the teaching pedagogies. The nature of media education requires a pupil-centred teaching approach where issues are explored, discussed, debated, analyzed, and presented. Media education pedagogy involves dialogue, a media discourse where pupils are encouraged to share their views and debate with fellow pupils and teachers on different issues to seek clarifications and answers. Through the process of analyzing media messages, pupils will engage in reflective thinking, a way to critical autonomy. Lastly, action will take place, which could be in the form of media production, such as producing a newspaper or setting up a campus radio or television station. 
The teaching of Media Education in moral lessons is thus effective as it goes into the hearts of pupils, with examples that they understand and can easily identify with. Research done by Cheung and Law (2002) indicate that pupils can become more critical and informed, and able to employ skills and knowledge to interpret the powerful media messages that surround them, through the teaching of media education in moral education lessons. Similarly, Kutnick (1988) complained that little use was made of television and other media for moral educational purposes, arguing that in media education, pupils will be familiar with materials chosen from movies, songs, advertisements, and the like.

\section{The Empirical Case for Teaching Moral Education through Media Education}

The existing body of research on media education can be broadly divided into two. The first kind of research explores the impact of media education on pupils' cognitive skills and/or knowledge about the media. It was found, for instance, that a six-hour course in media education improves pupils' ability to separate fact from fiction in a media program (Dorr, Graves \& Phelps, 1980). Another study shows that media education increases students' ability to identify genre and syntactical structure in media programs (Anderson, 1983). More recently, Hobbs (2004) found that a four-week course in analyzing advertisements increased students' knowledge about the pre-production processes of advertising and enhanced their ability to identify target audience, persuasive devices, and the implied message of advertisements.

Although this first kind of research-focusing on the cognitive and epistemic impacts of media education-does not generate direct argument for linking media education with improvements in moral attitudes or behavior, the second kind of research-exploring whether media education helps to reduce students' vulnerability to negative media influences-provides much evidence in the vicinity. For example, Austin and Johnson (1997) found that media literacy training resulted in children's viewing of characters in alcohol advertisements as less similar to people they knew in real life and less desirable, resulting in a decreased desire to be them, and decreased likelihood to choose an alcoholrelated product. Another study found that media education that helps children analyze media messages glamorizing tobacco use is an effective tobacco prevention strategy (Bergsma \& Ingram, 2001). More generally, studies have shown that media education can reduce children's susceptibility to advertising influences and promote skepticism about advertising messages (Slater et al, 1996). The standard explanation of the effectiveness of media education in this regard is in terms of the idea of cognitive defenses (Rossiter \& Robertson, 1974), according to which children can become capable of resisting advertising influence by understanding the selling intent of ads and the persuasive techniques employed therein.

The key question here is whether these findings can be generalized to the moral realm. From the fact that media education reduces students' vulnerability to tobacco and alcohol advertising, can it be inferred that a media literate person is also less prone to imitating the violence, cruelty, sexual promiscuity, dishonesty, self-centeredness, cynicism and so forth that permeate much of the contemporary media scene? In other words, can media education help achieve the aims of moral education by helping students resist the corrupting influences of mass media?

The present study was designed as a first step toward answering this question. It sought to determine whether media education can help improve students' moral attitudes and behavior by giving them the tools which may enable them to resist negative media influences in the moral realm, to analyze and critically examine media messages. The study examines the outcome of two separate media education programs, one in a primary school and the other in a secondary school. 


\section{i) The primary school}

The primary school in this study was awarded a sum of money from the Quality Education Fund to set up a campus radio since there was a training need for pupils in media production. Teachers in the school concerned were aware of what media education is and its potential to help pupils develop critical thinking skills; thus, they thought that it was a good opportunity to develop media education. Therefore, besides the setting up of the campus radio, a total of eight media education lessons on the topic of songs, TV, advertisements and newspaper were also held for Primary Five pupils in moral lessons.

A study was conducted to evaluate the project. Questionnaires and interviews were used as instruments to collect data. First a quantitative questionnaire survey was conducted for collecting general and standardized data from pupils. It was followed by several interviews. The interviewees consisted of parents, teachers and pupils randomly chosen.

To find out whether media education can help students resist corrupting media influence, the questionnaires and the interviews were designed to test the effectiveness of the project on the following three measures:

- whether students show increased awareness of the influence of media message on their moral values

- whether students develop negative attitudes toward media messages that implicitly or explicitly promote anti-social attitudes (such as callousness) and behavior (such as violence).

- whether students display an increase in ethical behavior as a result of increased awareness of media influence and negative attitudes toward media messages.

The measures adopted here are analogous to those commonly used in studies assessing the effectiveness of media education as a tobacco, alcohol or drug prevention strategy (Bergsma \& Ingram, 2001). The parallelism is not gratuitous: like those studies, the present study is premised on the theory of cognitive defenses which states that the more one knows about something, the more one will be able to defend oneself against its influence-whether it is a tobacco commercial, a sexually titillating TV scene, or a movie glamorizing criminal violence.

\section{The Findings}

From the interviews, it was noted that pupils, through lessons of media education, came to understand the moral importance of respecting one another. One particular incident was cited by a parent. She said that she and her son used to enjoy watching a local popular game show. One part of the show involved people teasing each other by telling the audience the shortcomings of one another. They had laughed while watching it before, but now her son reminded his parents they were laughing at others' misfortunes. A pupil, quoting a similar example, gave a more detailed reflection:

I treat TV as a kind of entertainment before but after the lesson I am more aware of what I am watching. For example, I like to watch game show and I think it is very entertaining and funny. It makes me laugh. But now I have a different view. In order to win the game, you have to say something bad about others. We hurt each other.

Teachers had also observed the change in pupils' behaviour. Teacher A, an experienced teacher, commented:

I have been teaching for 20 years and I find that the behaviour of the pupils is getting worse and worse. The trouble is they are too young to know what is right and what is wrong. But when the teachers tell me what to do, they do not listen. Through these few lessons of media education, I could see that through discussion of issues, points were made from both sides and for once pupils really 
listened. Pupils nowadays are influenced too much by the media, but if I only tell them what is bad about the media, they would not listen. Now, through media education when the teaching contents are familiar to them, we could explore together the messages and values conveyed. It is a good way to conduct moral education.

Media education is successful in helping pupils developing their ability to discern. From the questionnaire, around $70 \%$ of the pupils surveyed stated that they are more aware of the message conveyed by some and a similar number were more conscious of the influence of advertisements on them after media education lessons. The following comments from the interviews with pupils illustrate the significance of these points:

I used to listen to songs as a form of relaxation. Now I am more aware of the lyrics.

Too bad most of the local popular songs are about love. Life is more than boy-girl affair.

I used to believe in the advertisements but now I know a lot of them are exaggerations.

There are many advertisements telling women how they should look, and especially preaching the importance of being slim.

\section{ii) The secondary school}

The secondary school in this study is a school of long history, famous for its pupils' good academic performance. However, though pupils could get good results in examinations, teachers have found that the behaviour of pupils was unacceptable. In the recent curriculum reform, the importance of moral education was stressed, and the principal decided to take this opportunity to put more emphasis on moral education. According to the principal, moral education is done in the school through daily morning assembly and moral lessons. The former gave people such as the principal, disciplinary master and counseling master a chance to 'teach' pupils values while the latter is scheduled in the timetable for continual and proper teaching of moral education. However, that does not seem to work. For the former, the principal noted that pupils lose attention very quickly and the one-way communication could only result in the teaching of moral education. Whether pupils could learn it is another matter. Similarly, the traditional moral lessons scheduled in the timetable did not appeal to pupils. 'Young people are rebels, and do not want to be told how to behave in a moral manner,' exclaimed the principal. The researcher met the principal at a conference on media education and she wanted to seek other means to teach moral education. Thus the researcher was invited to work as a consultant to help teach moral education through media education.

\section{Process}

A total of five lessons of media education were taught in S. 2 moral lessons. S.2 pupils were chosen as they were found to be the most problematic in terms of behaviour and the time allowed for adoption of media lessons is more flexible as junior form pupils need not be bound by the syllabus and they are not yet under examination pressure.

A typical media education lesson would begin with the teacher presenting a media message from any form of media such as a news report from a newspaper or an advertisement broadcast on TV. The teacher then discussed with pupils the interpretation of the media messages. During the discussion, teachers would avoid giving 'model answers' and expressing value judgments, so as not to influence their pupils' thought. After each lesson, pupils were required to respond to the following three questions on the reflection sheet: 1) What did you learn from this lesson? 2) Have you learned anything today which differs from how you used to think? 3) Do you have other comments on this lesson? 


\section{The Findings}

\section{i. Response from reflection sheets}

In responding to Q.1, pupils' typical answers are:

Not every piece of news is believable.

The main purpose of advertisements is to sell products.

I realize it is important to read different newspapers to look at things from different angles.

For Q.2, pupils have strong reaction towards advertisement and a popular TV game show. The following are extracts from the comments:

I used to believe in the advertisements but now I know they use a lot of tricks to get me to spend my money.

After watching advertisements previously, I was tempted to buy the advertised products. Now I will think twice to see whether I really need to buy the product.

Before this lesson, I thought it was important to stay slim as a girl. But now I know the most important thing is to stay healthy, not to fall into the temptation of trying out products suggested by the advertisements to reduce weight. There might be harmful effects.

I used to like the game show because it made me laugh, but after the lessons I realized that sometimes I laughed at the misfortune of others.

For answers to Q.3, the following answers appear frequently:

The lessons are interesting.

I would like to have more lessons like this.

I enjoy the lessons as the things taught are familiar to me.
The reflection questions did not ask pupils to examine whether they had learned any moral values, to avoid them giving answers just to impress their teachers. However, there are quite a number of responses indicated that they had indeed learned moral values through these lessons. The following are a few examples:

From these lessons, I suddenly realized that there are a lot of advertisements on making your body slim. While it is fine for the advertisements to show the beauty of being slim, it is bad to look down on fat people.

When I read the newspaper now, I felt sick to see the front page showing photos of victims. We should feel sorry for those unlucky people who experienced tragedies. The newspaper should consider the feelings of the victims.

After going through the lessons, I still watch the TV game show, but with a different attitude. While it is interesting to see people making fun of each other, I now sympathize more with the losers. They lose the game and are made fun of by others.

\section{ii. Interview with teachers}

Two teachers were assigned to teach these media lessons and from the interviews, the following were noted.

a. Learning moral values through adopting the teacher's ideas

The reflection sheets show that pupils paraphrase teacher's ideas. Teacher Acommented:

It was noted from the reflection sheets that a lot of pupils paraphrased the teachers' ideas. Though I have reminded myself not to put in any 'model' answers or value judgment, pupils paraphrased my ideas and wrote some morally 'correct' answers. 
Paraphrasing requires a certain degree of understanding. Pupils who can rephrase the teacher's point of view in their own words demonstrate that they can grasp the teacher's ideas and have moved a bit away from 'spontaneous concepts' towards 'scientific concepts,' provided by the teacher, about the media messages (Vygotsky, 1978). Furthermore, if moral understanding can be linked with the capacity for moral reasoning (as seems fairly plausible), then pupils' ability to paraphrase moral ideas may indicate genuine moral improvement, insofar as numerous empirical studies have supported the correlation between levels of moral reasoning and prosocial behavior (e.g. Rest, Narvaez, Bebeau \& Thoma, 1994; Sheehan, Husted, Candee, Cook \& Bargen, 1980).

Besides paraphrasing the teachers' ideas, teacher B commented that 'many pupils can develop from understanding the teacher's point of view to presenting their own thinking, and to a certain extent, some degree of critical thinking'. Teacher A stated that 'it is a good sign as after critically evaluating what the media messages convey, pupils engage in reflection, leading to a change in their behaviour.

\section{b. Learning moral values through examining media messages}

Both teachers agreed that on the surface, at least from the reflection sheets, pupils become active examiners of media messages and their embedded values are conveyed. Teacher A commented:

It is difficult to say whether pupils behave better after only 5 lessons, but at least I could see that they are actively engaged in discussion with teachers during the lessons to explore the values behind the media messages.

Teacher B echoed:

The contents of discussion would be around some moral values and I could see that in the past pupils resented to listening to values but now through media education, I could make use of the lessons to clarify some moral issues with them.

Teacher A further elaborated:

I do think that there is a change in pupils. I gave you an example. Previously when we played group games in occasions like class picnic, pupils imitated what they saw from $T V$. But last week when we had gathering and some pupils suggested playing that kind of games, others quickly pointed out that it is dehumanizing. A pupil even pointed out TV game shows put players into the victims of the game in a sense that in order to win, they have to be humiliated in the name of entertaining the audience.

Both teachers were impressed by the general reaction of pupils to the media lessons and were confident that moral values would be learnt by the pupils. Besides moral values, both teachers claimed that pupils became more analytical and critical in exploring issues. They would suggest to the principal to have media education implemented into the curriculum and taught in moral lessons.

\section{DISCUSSION}

The above two cases were different in the beginning. The primary school started off with the idea of a campus radio and because some teachers were aware of what media education is, it was decided to have media education implemented into the curriculum through moral lessons, because of its flexible timetable and schedule. The secondary school, in exploring ways to teach moral values, tried it out through media education.

After implementing a few lessons of media education through moral lessons, evidence showed that pupils were more attracted to the lessons because of the familiar contents 
delivered in lessons, and became more aware of the moral values, though not explicitly taught, through exploring issues upon critical reflection. Teachers from both schools were convinced to further implement media education into their curriculum, and doing it through moral lessons is their first choice.

\section{LIMITATIONS}

Since media education is not an official subject, only a few schools in Hong Kong have tried it out. Among the few, the two schools in this study were identified. Though the findings may be not able to generalize situation in Hong Kong, it could definitely shed light on the relationship between the teachings of moral education through media education and provide contribution to further research.

\section{CONCLUSION}

Recent education reform in Hong Kong has called for a shift in pedagogy, in which teachers become knowledge facilitators rather than, as in the past, knowledge providers, and engages in a systematic study of their own teaching and learning practices. Schools are now dealing with pupils moulded by the media, which has become the most influential force shaping our pupils' world view and values.

Under these circumstances, the teaching contents and pedagogy need to be revisited where updated examples from the media are used and pupils are encouraged to discuss issues arising from these examples to see the underlying values and make decisions themselves after critical reflection. This is especially the case in the teaching and learning of moral education. It is no use for teachers to just tell pupils what is right and wrong. Cox (1983) noted that in this world of pluralistic confusion it is important for education to be a means to let pupils know what choices are available and help them to realize the implications of making such choices rather than teaching moral education merely as facts and statements. Pupils should be given opportunities to make choices, including moral ones, and schools should be encouraged to provide avenues for pupils to freely discuss and explore the rights and wrongs of these choices. Since pupils are familiar with the examples taken from their daily consumption of media messages, they would welcome media education. By combining pleasure with the acquisition of knowledge, the classroom will be filled with an atmosphere of discovery and investigation, and pupils' minds will become critical and evaluative.

Using moral education lessons to teach media education has its advantages. For one thing, the moral education syllabus is more flexible and some of the goals of media education seem very similar to those of moral education. Besides, media education does not rely on a fixed textbook. As the teaching materials of media education usually relate to current happenings on television, movies and in newspapers and magazines, the discussion of values related contemporary issues is a prerequisite in the teaching of moral education. Furthermore, the nature of moral education gives rise to a more pupil-centred teaching approach, which is a must in the teaching of media education. The two studies in this paper provided good evidence.

As our society is being transformed from an industrial society into a knowledge society, the Education Commission (1999, p.5) suggests that learning is no longer confined to school subjects or limited to classrooms. If we, as educators, have the mission to equip pupils with life skills for coping with the world outside the classroom and beyond schooldays, we should feel the pressing need of media education for all pupils. The media education curriculum will enable pupils to construct knowledge and develop a global outlook to cope with the changing and interdependent world in the 2lst century, and develop a pupil's lifelong learning skills (to enjoy learning, to enhance effectiveness in communication, to develop creativity, to develop a logical, critical, and an analytical mind) as stipulated in the aims of education. Furthermore, 
the role of moral educators regarding the media is not to denigrate media artifacts so pupils will switch off the television. Instead, their role is to assist in the development of their understanding of the media messages, and values and ideologies. This refers to the learning and teaching of moral education through media education.

Considine (2002) warned that while pupils have access to many different forms of media, they do not necessarily possess the ethics, the intellectual skills, or the predisposition to critically analyze and evaluate their relationship with these technologies or the information they encounter (p.24)'

\section{ACKNOWLEDGEMENT}

This paper was funded by the Small project funding program from the University of Hong Kong and the author wishes to thank his research assistant Yu Guo.

\section{REFERENCES}

Anderson, J. A. (1983). The theoretical lineage of critical viewing curricula. Journal of Communication, 30 (3), 64-70.

Austin, E. \& Johnson, K. (1997). Effects of general and alcohol-specific media literacy training on children's decision making about alcohol. Journal of Health Communication, 2 (1), 17-42.

Bergsma, L. \& Ingram M.(2001). Blowing Smoke: Can media literacy impact youth smoking? Arizona Department of Health Services. Retrieved 10 February, 2007 from http:// ww w.medialit.org/reading_room/ article420.html.

Bassett, Liz. (2000). A "skillful" approach to the teaching of Religious Education. RE Source, 22(2), 10-12.

Browning, D.S., Miller-McLemore, B.J., Couture, P.D., Brynoff Lyon, K., \& Franklin, R.M. (1997). From culture wars to common ground: Religion and the American family debate. Louisville, KY: Westminster John Knox Press.

CDC (1999). Syllabuses for secondary schools: Religious education secondary 1-3. Government Printer: Hong Kong.

CDC (2001a). Learning to learn: report on the direction of the curriculum development. Government Printer: Hong Kong.

CDC (2001b). Personal, social and humanities education key learning area: ethics and religious studies. Government Printer: Hong Kong.

Cheng, F.T. (1951). Confucianism. In J. A. Lauwey's \& N. Hans (Eds.), The year book of education 1951 (pp.252-261). London: Evan Brothers.

Cheung, C.K. (2003). The use of popular culture in the teaching of ethics/religious education-A Hong Kong case. Religious Education, 98(2), 197-220.

Cheung, C.K. (2004). Media education in Hong Kong schools: possibilities and challenges. Educational Studies, 30(1), 33-52.

Cheung, C.K. (2006). Media education as a vehicle for teaching religion - a Hong Kong case. Religious Education, 101(3).

Cheung, C.K. \& Law, S.L. (2002). Implementing media education in secondary curriculum: a Hong Kong experience. The Asia Pacific Education Researcher, 11(2), 161-176.

Considine, D. (2002).Media literacy across the curriculum. Retrieved September 5, 2006, fromhttp://www.ciconline.org/NR/ rdonlyreseb3vg6zhcpg5xlf6lsrxack3f3z67keuqjsfx4 zptiljbrkdqezhlpwgzgtucxjkiqiyfpvcbijg5uxhuet67ls6jfe/CICML-Considine.pd

Cox, E. (1983). Problems and possibilities for religious education. London: Hodder and Stoughton.

Crawford, M.L., \& Rossiter, G.M. (1988). Missionaries to a teenage culture. Sydney: Christian Brothers Province Resource Group.

Dorr, A., Graves, S. \& Phelps, E. (1980). Television literacy for young children. Journal of Communication, 30 (3), 71-83. 
Education Commission (1996). Report no.7. Hong Kong: Government Printer.

Education Commission (1999). Education blueprint for the $21^{\text {st }}$ century. Hong Kong: Government Printer.

Education Department (1981). General guidelines on moral education in schools. Hong Kong, Government Printer.

EMB (1993). School education in Hong Kong: a statement of aims. Hong Kong: Government Printer.

Hobbs, R. (2004). Does Media Literacy Work? An Empirical Study of Learning How to Analyze Advertisements. Advertising \& Society Review, 5(4), $1-28$.

IFTC (1977). 'Preface'. In International Film and Council (Ed.), Media studies in education (pp.3). Paris: UNESCO.

Kutnick, P. (1988) 'I'll teach you!' Primary school teachers' attitudes to and cure of moral education in the curriculum. Journal of Moral Education, 17(1), 40-51.

Marples, R. (Ed). (1999). The aims of education. New York: Routledge.

Masterman, L. (1992). A distinctive mode of enquiry: towards critical autonomy. In: M. Alvarado \& Oliver Boyd-Barrett (Eds.), Media education: an introduction, (pp.102-103). London: BFI.

Minkkinen, S. \& Liorca, J.M. (1978). A general curricular model for mass media education. Paris: UNESCO.
Niblett, W.R. (1963). Moral education in a changing society. London: Faber and Faber.

Rest, J., Narvaez, D., Bebeau, M. J., \& Thoma, S. J. (1999). Postconventional moral thinking: A Neo-Kohlbergian approach. Lawrence Erlbaum Associates: Mahwah, NJ.

Rossiter, J. \& Robertson, T. (1974). Children's TV commercials: testing the defenses. Journal of Communication, 24, 137-144.

Sheehan, T. J., Husted, S., Candee, D., Cook, C. D., \& Bargen, M. (1980). Moral judgment as a predictor of clinical performance. Evaluation in the Health Professions, 3 (4), 393-404.

Slater, M., Rouner, D., Murphy, K., Beavais, F., Van Leuven, J. \& Domenech-Rodriguez, M. (1996). Adolescent counterarguing of TV beer advertisements: Evidence for effectiveness of alcohol education and critical viewing discussions. Journal of Drug Education, 26 (2), 143-158.

Stout, D.A. (2001). Beyond culture wars: an introduction to the study of religion and popular culture. In Daniel A. Stout \& Judith M. Buddenbaum (Eds.), Religion and popular culture: studies on the interaction of worldviews. Ames, Iowa: Iowa State University Press.

Vygotsky, L.S. (1978). Mind in society: the development of higher psychological process. Cambridge, Mass.: Harvard University Press.

Whitehead, A.N. (1967). The aims of education, and other essays. New York: Free Press. 